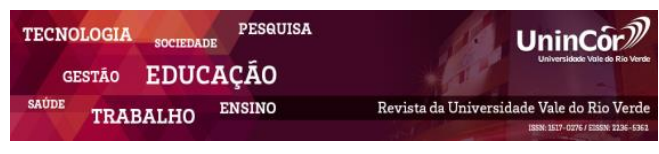

Revista da Universidade Vale do Rio Verde
ISSN: $1517-0276$ / EISSN: 2236-5362
v. 17 | n. 1 | Ano 2019

Sthanley Ogino Zaqueu

Universidade Vale do Rio Verde - UNINCOR

E-mail: sthanleyogino2@hotmail.com

Cilene Margarete Pereira

Universidade Vale do Rio Verde - UNINCOR

E-mail: prof.cilene.pereira@unincor.edu.br

\section{TEMAS E TONS DA CANÇÃO DE PAULINHO DA VIOLA ${ }^{1}$}

\section{RESUMO}

Este artigo apresenta os resultados finais do projeto de Iniciação Científica "Temas e tons da canção de Paulinho da Viola", que buscou fazer um levantamento temático da produção musical do compositor carioca Paulinho da Viola entre as décadas de 1960 a 2010, tendo como ponto de partida o álbum autoral Paulinho da Viola, de 1968. O corpus da pesquisa foi dividido em dois grandes blocos: o primeiro correspondeu aos dez primeiros álbuns do compositor carioca, gravados entre 1968 e 1979, período no qual o compositor dá início à sua produção solista e que apresenta um momento fecundo e produtivo em sua carreira, com o lançamento de quase um disco por ano. No segundo bloco, trabalhamos com os nove álbuns lançados nas décadas de 1980, 1990 e 2000, segundo informações retiradas de seu site oficial. Algumas perguntas direcionaram o projeto, a saber: (1) quais são, de fato, os temas do cancioneiro popular de Paulinho da Viola? (2) como estes temas são tratados em suas canções? (3) estes temas derivam do universo musical ao qual o compositor se associa, o samba? (4) que tipo de canções formatam estes temas? (5) é possível depreender, do levantamento temático, o tema dominante do cancioneiro do compositor? Este artigo busca responder as questões propostas pelo projeto, mapeando os temas e tons da canção de Paulinho da Viola.

Palavras-chave: Paulinho da Viola, samba, temas.

\section{THEMES AND TONES OF PAULINHO DA VIOLA'S MUSIC}

\section{ABSTRACT}

This article presents the final results of the Scientific Initiation Project "Themes and tones of Paulinho da Viola's music", which sought to collect theme data of the musical composer from Rio Paulinho da Viola between the decades of 1960 to 2010, having as bottom line the authorial album Paulinho da Viola,

\footnotetext{
1 Uma versão inicial deste texto foi publicada nos Anais do VIII Encontro Tricordiano de Linguística e Literatura, realizado pelo Departamento de Letras da Universidade Vale do Rio Verde. O trabalho foi agraciado com prêmio de Menção Honrosa na XX Mostra de Iniciação Científica da Universidade Vale do Rio Verde, realizada em nov. de 2018.
} 
from 1968. The research corpuswas split into two big blocks: the first one corresponded to the ten first albums of the composer from Rio, recorded between 1968 and 1979, during which period the composer started his solo production and it represents a fertile and productive moment in his career, by launching almost a record a year. In the second block, we worked with nine albums launched in the decades of 1980 , 1990 and 2000, according to information taken from his official website. Some questions directed the Project, such as: (1) which are, in fact, the themes of the popular songbook by Paulinho da Viola? (2) how are such themes treated in his songs? (3) do such themes derive from the musical universe to which the composer associates himself with, the samba? (4) what kind of songs format those themes? (5) is it possible to understand, from the theme data collection, the dominating theme of the composer's songbook? This article aims at answering the questions proposed by the Project, mapping the tones and themes of Paulinho da Viola's music.

Key words: : Paulinho da Viola, samba, themes.

\section{Recebido em: 20/11/2018 - Aprovado em: 19/03/2019 - Disponibilizado em: 15/07/2019}

\section{$[\ldots]$}

O samba é alegria,

Falando coisas da gente, Se você anda tristonho,

No samba fica contente

$[\ldots]$

("Eu canto samba" / Paulinho da Viola)

\section{[...]}

Quem quiser que pense um pouco

Eu não posso explicar meus encontros

Ninguém pode explicar a vida

Num samba curto

("Num samba curto" / Paulinho da Viola)

\section{[...]}

Quase sempre um coração amargurado

Pelo desprezo de alguém

É tocado pelas cordas de uma viola

É assim que um samba vem

[...]

("Quando bate uma saudade" / Paulinho da Viola)

Este artigo deriva da pesquisa de Iniciação

Científica Temas e tons da canção popular brasileira: um estudo da obra de Paulinho da Viola, coordenado pela Profa. Dra. Cilene Pereira, que buscou fazer um levantamento temático da produção musical do compositor carioca Paulinho da Viola entre as décadas de 1960 a 2010, tendo como ponto de partida o álbum autoral Paulinho da Viola, de 1968.

Para melhor organização dos dados, o corpus da pesquisa foi dividido em dois grandes blocos: o primeiro correspondeu aos dez primeiros álbuns do compositor, gravados entre 1968 e 1979. Este período foi escolhido não só por dar início à produção solista do compositor, que começa efetivamente com álbuns assinados apenas por ele, mas por se apresentar como um momento fecundo e produtivo em sua carreira, com o lançamento de quase um disco por ano. Nos anos de 1971 e 1976, por exemplo, dois álbuns foram lançados no ano. Em relação aos álbuns de 1976, Memórias 1 - cantando e Memórias 2 - chorando, lançados simultaneamente em dezembro daquele ano, destaca-se que apenas o primeiro fez parte do 
corpus desta pesquisa, uma vez que o segundo, dedicado ao choro - outra paixão de Paulinho ${ }^{2}$ - é apenas instrumental. ${ }^{3} \quad$ No segundo bloco, trabalhamos com os nove álbuns lançados nas décadas de 1980, 1990 e 2000, segundo informações retiradas de seu site oficial. ${ }^{4}$

Filho do músico Cesar Faria, Paulinho da Viola cresceu num ambiente naturalmente musical. Na sua infância em Botafogo, bairro tradicional da zona sul do Rio de Janeiro onde nasceu em 12 de novembro de 1942, teve contado constante com a música através do pai, violonista integrante do conjunto Época de Ouro. Nos ensaios familiares do conjunto, Paulinho conheceu Jacob do Bandolim e Pixinguinha, entre muitos outros músicos que se reuniam para fazer choro e eventualmente cantar valsas e sambas de diferentes épocas. ${ }^{5}$

A trajetória musical de Paulinho da Viola concentra canções que se tornaram clássicos de nosso cancioneiro, notadamente do samba, gênero musical que tem como "principal elemento

\footnotetext{
${ }^{2}$ João Máximo observa, a respeito dos discos, que "Era como se quisesse deixar claro que os dois rios, seus dois mundos musicais, o do samba do primeiro LP e o do choro do segundo, eram formalmente distintos um do outro, mas que podiam coexistir de maneira exemplar, se tratados por artista como alma de sambista e chorão como a sua" (MÁXIMO, 2002, p. 94). Em seu site oficial, lemos o seguinte: "Paulinho compõe nas formas de sambas, choros e experimentações. O samba é a forma principal, maternal do artista. O choro é a forma herdada do pai, um sofisticado estilo instrumental, quase erudito. A experimentação surgiu para atender ao desejo de dar vazão a um sentimento de busca por novas formas, traço comum do artista." Disponível em: http://www.paulinhodaviola.com.br/portugues/a_music a/a_musica.asp. Acesso em 14 de out. 2018.

3 A respeito desse lançamento duplo no ano de 1976, José Ramos Tinhorão declarou: “Após alguns anos de carreira, qualquer cantor, músico ou compositor começa a pensar seriamente na possibilidade de produzir ao menos um disco perfeito. Pois Paulinho da Viola acaba de conseguir dois - de uma vez!" (TINHORÃO apud MÁXIMO, 2002, p. 94).

${ }^{4}$ Disponível em: http://www.paulinhodaviola.com.br/portugues/discogra fia/discografia.htm. Acesso em 21 de fev. 2018.

${ }^{5}$ Disponível em:

http://www.paulinhodaviola.com.br/portugues/biografi a/biografia.asp. Acesso em 11 de out. 2018.
}

rítmico [...]a síncope. Esta divisão rítmica, comum aos ritmos africanos, encontrou no Brasil um campo fértil para a sua utilização. Nenhuma outra cultura absorveu a síncope como a brasileira. Se o jazz descobriu e encorporou o swing, o samba já nasceu sincopado." ${ }^{\circ}$ A respeito da síncope ou síncopa, Muniz Sodré observa essa "alteração rítmica que consiste no prolongamento do som de um tempo fraco num tempo forte", era também conhecida pelos europeus, sendo, no entanto, na Europa, "mais frequente na melodia", enquanto que na África "sua incidência básica era rítmica" (SODRÉ, 1998, p. 25)

Sambas de Paulinho da Viola como "Coisas do mundo, minha nega"; "Foi um rio que passou em minha vida"; "Sinal fechado"; "Dança da solidão"; "Comprimido"; "Roendo as unhas", 8

\footnotetext{
${ }^{6}$ Disponível em:

http://www.paulinhodaviola.com.br/portugues/a_music a/a_musica.asp. Acesso em 11 de out. 2018.

7 "Sinal Fechado é um evento raro. Fundiram-se nesse ponto de 1969 a música erudita moderna e o samba. Não é difícil imaginar que Paulinho da Viola ouvia obras de compositores como Malcon Arnold, como ele nos confirma, mas sinal fechado não é apenas uma experimentação ou uma fusão bem sucedida de concertos modernos com a música brasileira. É algo mais. Muitos pensam que a letra dessa música é um retrato da vida urbana na época da ditadura militar brasileira, que no ano anterior tinha realizado o seu pior evento até então ao suprimir os direitos constitucionais do cidadão através do AI-5. A ditadura acabou há tempos e um novo olhar nos mostra que esta obra não foi superada na forma, no conteúdo, na experiência estética e na abrangência de sua letra. Sinal Fechado faz mais sentido hoje do que quando foi composta. A estética fria e tensa não nos é mais tão estranha. É o hino do desencontro, do mundo contemporâneo, das cidades movimentadas, dos sinais fechados sempre presentes que nos forçam a observar as pessoas por dentro dos carros, da vida urbana, da necessidade de se buscar um lugar no futuro. Sinal Fechado já buscava seu lugar no futuro quando foi composta e certamente conseguiu."

Disponível em:

http://www.paulinhodaviola.com.br/portugues/a_music a/a_musica.asp. Acesso em 11 de out. 2018.

${ }^{8}$ Em "Roendo as unhas", "Em sua forma nada é fixo, não há chão, há apenas os deslocamentos. É impossível determinar a nota dominante, ela não existe. O que vemos é uma sucessão de momentos que se envolvem e
} 
“Argumento", entre tantas outras são, hoje, clássicos do gênero. Por meio deste repertório, é possível vislumbrar alguns temas, tais como "pensar sobre o mundo"; o amor à escola de samba e ao carnaval, a incomunicabilidade entre as pessoas; as relações humanas e amorosas; o cotidiano massacrante de um casal; o fazer artístico; a relação entre tradição e modernidade, por exemplo.

Mas quais são de fato os temas que circundam as canções de Paulinho da Viola? Para respondermos a essa pergunta central, alguns questionamento direcionaram a pesquisa, tais como: (1) quais são os temas do cancioneiro de Paulinho da Viola? (2) como estes temas são tratados em suas canções? (3) estes temas derivam do universo musical ao qual o compositor se associa, o samba? (4) que tipo de canções formatam estes temas? (5) é possível depreender, do levantamento temático, o tema dominante do cancioneiro do compositor?

Entre os anos de 1968 a 2003, Paulinho da Viola gravou 288 canções, das quais 15 foram instrumentais, 54 gravadas em mais de um álbum e 98 de outros compositores. Destes compositores, os mais gravados foram Élton Medeiros e Cartola (2 Canções), Cartola (7 Canções), Élton Medeiros (2 Canções), Monarco (5 Canções), Nelson Cavaquinho (4 Canções). Como vemos, todos são sambistas consagrados, ligados a duas importantes escolas de samba, Estação Primeira de Mangueira e Grêmio Recreativo Portela, escola do coração de Paulinho.

criam um ciclo de inúmeras possibilidades. O sambista ganha um olhar profundo, filosofa sobre sua relação com a música e caminha pelas ruas com sua 'flor nenhuma'. A angústia de um momento de transformação da nossa história não poderia estar melhor representada." Disponível em: http://www.paulinhodaviola.com.br/portugues/a_music a/a_musica.asp. Acesso em 11 de out. 2018.
Das 288 composições gravadas nesse período, 121 canções são de sua autoria: 86 compostas individualmente e 35 em parcerias. Seus parcerios mais frequentes foram Élton Medeiros (12 canções), Capinam (8 canções) e Sérgio Natureza (6 canções). Destas parcerias, destacamos "Nova alegria", do álbum Paulinho da Viola, de 1975, composta com Elton Medeiros, canção que aborda um tema caro ao cancioneiro de Paulinho, o amoroso, a partir de duas realidades: a frustração amorosa e a incidência de um novo amor.
Afinal, uma nova alegria
Surgiu dentro do meu coração
Eu que não pensava mais viver um novo amor
pra não sofrer outra desilusão $[\ldots]$

Mapeando os temas das canções compostas apenas por Paulinho da Viola, identificamos quatro grandes temas, presentes em 86 composições individuais, dispostos da seguinte maneira. Ao tema amoroso são reservadas 39 canções, sendo que o tema específico da "frustração amorosa" está presente de maneira direta em 28 canções. Em 2 canções, aparece a ideia de um "novo amor"; em outras 3, o tema do "amor impossível", devido à distância ou à não correspondência, em 4, o desejo de "'reatar o amor', e em 2 canções, temos a ideia de "amor bem sucedido".

Nesse caso, é possível dizer que o tema amoroso é uma das tópicas maiores do cancioneiro de Paulinho da Viola, e que quando canta o amor, o compositor ressalta o "fracasso das relações amorosas", conforme vemos no samba "Não quero vingança", gravado no álbum Paulinho da Viola, de 1981:
Não quero vingança
Eu não
O que você me fez 
Juro que já perdoei

Não é fácil a gente se livrar

De uma ingratidão

Mas desta, graças a Deus me livrei

$[\ldots]$

Um segundo tema de importância em seu cancioneiro é reservado ao próprio gênero musical praticado por Paulinho da Viola, o samba. Das 86 canções de autoria individual, 11 têm o samba como elemento principal, seja discutindo a própria construção do samba (4 canções), seja enaltecendo o gênero (4 canções) ou sua escola de coração, a Portela (3 canções). A Portela é o tema, por exemplo, da famosa "Foi um rio que passou em minha vida", do álbum homônimo de 1970, na qual a escola é cantada como se fosse uma nova relação amorosa que surge na vida do eu lírico:

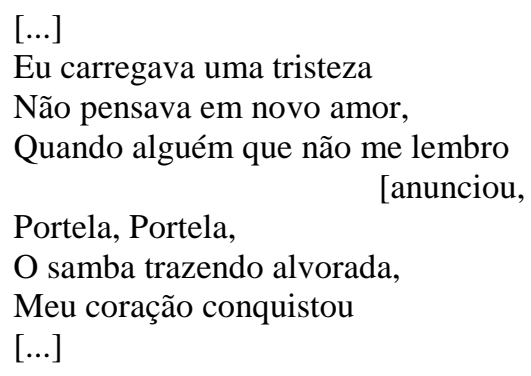

Devido a esse amor pela Portela, a escola pode aparecer também como elemento de desentendimento amoroso, como se dá no samba "Pra não contrariar você", do mesmo álbum:

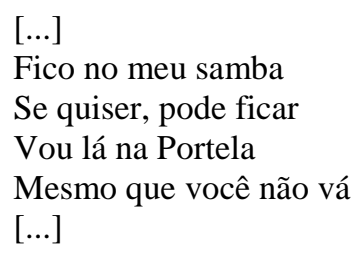

No samba "A gente esquece", do álbum Paulinho da Viola, de 1968, o compositor associa os dois temas citados, o amor frustrado e o samba, estabelecendo uma relação próxima entre ambos.
A gente esquece um samba
E faz um outro samba
A gente perde um grande amor
E acha um outro amor
Você morreu no meu peito
E no meu peito nasceu
Não um outro amor

\section{Mas essa indiferença sem saudade Sem tristeza e sem rancor $[\ldots]$}

Um terceiro aspecto que se destaca no cancioneiro de Paulinho é a descrição de personagens inseridas em situações cotidianas, o que dá a seu samba um tom narrativo. Das 86 canções de autoria individual, 10 são formatadas pela ideia de contar uma história a respeito de uma personagem, como vemos no samba "No pagode do Vavá", gravado no álbum $A$ dança $d a$ solidão, de 1972. Nesse caso, o que vemos é o uso de uma narratividade própria da canção popular, que trabalha com "os temas da vida concreta e cotidiana", com os quais o ouvinte pode se identificar (AZEVEDO, s/d, p. 17).
Domingo, lá na casa do Vavá
Teve um tremendo pagode
Que você não pode imaginar
Provei do famoso feijão da Vicentina
Só quem é da Portela é que sabe
Que a coisa é divina
Tinha gente de todo lugar
No pagode do Vavá
Nego tirava o sapato, ficava à vontade Comia com a mão
Uma batida gostosa que tinha o nome De doce ilusão
[...]

Em "O pagode do Vavá", o samba nasce do próprio encontro do samba, reafirmando, conforme observa Cláudia Matos,

[...] o objetivo mais imediato e manifesto do acontecimento-samba", visto que se trata "antes de mais nada de uma brincadeira, de uma fonte de prazer lúdico para os que dele participam" (MATOS, 1982, p. 31).

Inserido em temas cotidianos, podem aparecer tipos sociais, como se dá no samba "Papo furado", gravado no álbum Foi um rio que passou em minha vida, de 1970, consagrado a um tipo bem popular, o fofoqueiro:

Existe lá perto de casa um cara 
Seu nome eu não quero dizer

Que tem a mania muito devagar

De correr e contar

Tudo aquilo que ouve e vê

[...]

No samba "Comprimido", do álbum Nervos de aço, de 1973, "narra-se o cotidiano de um casal que vive às voltas com agressões e ocorrências policiais, tudo devido ao ciúme feminino, segundo observa o "narrador"' (PEREIRA, 2016, p. 7).

Deixou a marca dos dentes

Dela no braço

Pra depois mostrar pro delegado

Se acaso ela for se queixar

Da surra que levou

Por causa de um ciúme incontrolado

Ele andava tristonho

Guardando um segredo

Chegava e saía

Comer não comia

E só bebia

Cadê a paz

Tanto que deu pra pensar

Que poderia haver outro amor

$\mathrm{Na}$ vida do nego

Pra desassossego

E nada mais

$[\ldots]$

Este cotidiano, ao contrário de outros impressos em outras canções, é tratado de maneira dramática pelo compositor, que leva sua personagem masculina ao suicídio:

[...]

Uma noite Noite de samba

Noite comum de novela

Ele chegou

Pedindo um copo d'água

Pra tomar um comprimido

Depois cambaleando

Foi pro quarto

E se deitou

Era tarde demais

Quando ela percebeu

Que ele se envenenou

$[\ldots]$

Cilene Pereira observa que, na segunda parte da canção,

[...] acompanhando a dramaticidade do ato [do suicídio], temos um andamento melódico mais lento, com a voz de
Paulinho da Viola quase a capela, exceto por um tamborim marcando o compasso e por dedilhados de piano mimetizando o cambalear da personagem na estrofe anunciadora do suicídio. (PEREIRA, 2016, p. 9).

\section{Para Eliete Negreiros,}

[...] é de um cotidiano desencantado que irrompe a poesia de Comprimido, poesia gestual, onde o silêncio que envolve o mistério do personagem central é um silêncio 'comprimido', que explode na atitude radical da falta de sentido: a morte. Mas, ao mesmo tempo em que a morte do personagem traduz seu abandono fatal ao desencanto, à ausência de sentido, ela abala os pilares daquele mundo constituído, aponta as fraturas de uma ordem que não corresponde aos anseios de um homem comum, uma ordem que comprime os sentimentos e onde a morte aparece para ele como única possibilidade de libertação (NEGREIROS, 2011, p. 102).

Um quarto tema que se destaca no cancioneiro de Paulino da Viola são os questionamentos sobre a existência humana, conforme observa Francisco Romanelli (2014, p. 97-98). Para o ensaísta, Paulinho, em suas canções, entente o samba como espaço de manifestação da vida, por meio de um universo metafísico ou através do cotidiano simples (Cf. ROMANELLI, 2014, p. 98). No samba "Coisas do mundo minha nega", Romanelli identifica, por exemplo, que a divagação filosófica se dá no processo de buscar o que não se sabe ao certo, por isso o termo "coisas", inserido já no título da canção.

[...]

Hoje eu vim, minha nega

Sem saber nada da vida

Querendo aprender contigo

A forma de se viver

As coisas estão no mundo

Só que eu preciso aprender

As coisas estão no mundo

Só que eu preciso aprender

A personagem do samba 
Não tem ideia sobre o que exatamente busca, então, busca "coisas"; não sabe onde encontrá-las, então as procura "no mundo". As coisas estão no mundo: as indefinições perseguidas estão na vastidão de um todo perceptível, mas ele não as pode identificar nem percebê-las e se lança na perplexidade de buscá-las. (ROMANELLI, 2014, p. 107)

Outro modo de situar o tema filosófico na canção de Paulinho da Viola é apreender as metáforas utilizadas, sobretudo referentes à natureza, tais como o vento e o mar, como vemos em "Pra jogar no oceano", do álbum Paulinho da Viola, de 1981:

\section{$[\ldots]$}

O vento é quem tira a poeira de tudo

A gente lamenta e depois reconhece

Que o amor não se acaba nas dores do mundo

$[\ldots]$

Neste trecho da canção, aponta Romanelli, o vento tem a função de carregar tudo, todos os males, e é ele quem traz esclarecimentos à personagem. (Cf. ROMANELLI, 2014, p.115).

Associado ainda à metáfora da natureza, vemos a ideia de incontrolabilidade da vida (Cf. ROMANELLI, 2014, p.118) no famoso samba “Timoneiro", do álbum Bebadosamba, de 1996:
Não sou eu quem me navega
Quem me navega é o mar
É ele quem me carrega
Como nem fosse levar
$[\ldots]$

Nessa canção, o eixo primordial é a fala da personagem, sempre afirmando que não tem o controle da vida. Associada a este tema, sem fazer referência à natureza, aparece o belíssimo "Num samba curto", do álbum Paulinho da Viola, de 1971, no qual o eu lírico, notadamente um sambista, confessa humildemente que "Ninguém pode explicar a vida / Num samba curto".

Para Romanelli, o samba em suas nuances filosóficas pode ter funções distintas, podendo ser ferramenta para extravasar a dor existencial ou para sublimá-la, direcionando o sofrimento para a aprendizagem e o pensamento reflexivo e crítico. (Cf. ROMANELLI, 2014, p. 110). Para Luiz Pereira Júnior, filosofar seria, na canção de Paulinho "(de sua autoria e de adoção, ao interpretar temas de outros), um movimentar-se coerente pela concretude do mundo". (PEREIRA Jr., 2011, p. 15), assim como se dá em "Coisas do mundo minha nega".

Outros temas aparecem de modo mais tímido no cancioneiro do compositor carioca, como a ideia de passagem do tempo (3 canções) e questões relativas a dinheiro (1 canção). A canção "Só o tempo", do álbum A toda hora rola uma estória, de 1982, salienta que somente a passagem do tempo é capaz de ensinar sobre a forma de se viver:

\section{[...] \\ Por isso eu deixo em aberto \\ Meu saldo de sentimentos \\ Sabendo que só o tempo \\ Ensina a gente a viver}

No repertório musical de Paulinho da Viola, a canção "Pode Guardar as Panelas", do álbum Zumbido, de 1979, aparece aludindo sobre questões financeiras, especificamente, sobre a falta de dinheiro:
Você sabe que a maré
Não está moleza não
E quem não fica dormindo de touca
Já sabe da situação
Eu sei que dói no coração
Falar do jeito que falei
Dizer que o pior aconteceu
Pode guardar as panelas
Que hoje o dinheiro não deu
Dei pinote adoidado
Pedindo emprestado e ninguém
Fui no seu Malaquias [emprestou
Querendo fiado mas ele negou
Meu ordenado apertado, coitado, [engraçado
Desapareceu 
Fui apelar pro cavalo, joguei na cabeça Mas ele não deu

$[\ldots]$

Quando consideramos as canções de Paulinho da Viola com seus parcerios, um total de 35 canções, identificamos 3 temas gerais recorrentes, somados a alguns que ganham destaque em poucas canções, como reclamações ou o acaso da vida. Novamente, o amor invande o temário de Paulinho e seus parcerios, totalizando 13 canções, destancando, mais uma vez, o "fracasso amoroso", que aparece de maneira direta em 9 canções, e indiretamente em outras 4 canções, que exploram temas como a tentativa de reatar o amor e de um novo amor.

No samba "Sentimento perdido", parceria com Elton Medeiros, gravada no álbum Paulinho da Viola, de 1978, o tema do amor fracassado e do desejo amoroso não findo aparecem juntos:

Tirei

Do coração uma sombra esquecida, tirei [Jurei

Que nunca mais amaria na vida E assim

Pensei

Que havia em mim um sentimento [perdido

Não percebi quanto estava iludido E outra vez amei $[\ldots]$

O segundo tema de destaque é também reservado à história de personagens, como ocorre em 3 sambas: "Moema Morenou" (de Paulinho da Viola, de 1971/1972) e "Vela no breu" e "Dívidas" (de Memórias Cantando, de 1976). Em "Moema Morenou”, o espaço social explorado é o do samba, no qual se destaca a figura da mulata:

Moema Morenou

A água do mar que molhou

O sol da Bahia te queimou

Teu corpo morena morenou

No samba de roda

Morena faceira
Mexeu a cadeiras
Foi um desacato
Tirou o sapato
Dançou miudinho
E quase que mata
Um pobre mulato
[...]

Neste samba, enfatiza-se, observa Pereira Jr.,

[...] a dança sensual e o movimento ritímico do corpo como fatores da festa popular que se reconhece como roda de samba [...]. Samba de frase curtas e de aceleração de células rítmicas [...] Moema Morenou parece simular as condições de espontaneidade das rodas de bambas do passado, em que o refrão funciona como elemento guia do desempenho e e o batuque promove um ritmo ligado à farra e à festa (PEREIRA Jr., 2011, p. 26-27).

No mapeamento dos temas do cancioneiro de Paulinho da Viola e seus parcerios, chama a atenção o fato de que a exaltação ao samba sofre uma queda significativa, tendo sido encontrada apenas 1 canção destinada ao mote: o samba “Cantoria”, gravado no álbum Eu canto samba, de 1989, parceria com Hermínio Bello de Carvalho. Mesmo assim, o samba não é nomeado explicitamente, mas apenas o ato de compor e cantar, que, no caso de Paulinho e considerando o nome do álbum, rapidamente se associa ao samba.
Amar é um dom, há que saber o tom
E entoar bem certo a melodia
O povo enxerga a luz de uma voz sincera
E canta com ela em sintonia
Cantar é uma luz, um enfunar de velas
É compreender a canção como um navio
Que vai zarpando, ignorando mapas
Tocando as águas que nem harpas
Por conta do destino
[...]

Como vemos, o mapeamento de temas do cancioneiro de Paulinho da Viola, considerando suas composições individuais e parcerias, aponta como tema principal o amoroso, com 93 canções, sendo que o "fracasso no amor" ganha destaque, 
totalizando 68 canções. $\mathrm{O}$ tema do amor que não deu certo perpassa todos os álbuns do compositor.

Considerando a importância do tema amoroso do cancioneiro de Paulinho da Viola, chama a atenção que apenas duas canções do compositor se reportem, de maneira mais direta, ao tema do amor bem sucedido: os sambas "Retiro", do álbum Prisma Luminoso, de 1983, e "Pintou um bode", do disco Eu Canto Samba, de 1989.

Na primeira, a letra faz referência a uma satisfação plena do eu lírico em estar com a amada:

$$
\text { [...] }
$$

Nos momentos de carinho Eu me desligo de tudo Nos braços de quem se ama É fácil esquecer o mundo [...]

O tema do amor bem sucedido está presente no fato que este não se esmoreceu ou acabou com o tempo, segundo observa o eu lírico:
Meu tempo às vezes se perde
Em coisas que não desejo
Mas não repare esse lado
Pois meu amor é o mesmo $[\ldots]$

$\mathrm{Na}$ letra, a figura amorosa aparece como "lugar de refúgio", no qual o eu lírico recorre para dar sentido à sua própria existência:

[...]
Só há um canto na vida
Aonde eu me refugio
Afasta as sombras que eu vejo
Em teus olhos tão aflitos
Você conhece minh'alma
E quando quer me visita

A letra da canção, "Pintou um bode", associada ao tema "amor bem sucedido" trata de um personagem malandro que passa por dificuldades financeiras e percebe que precisa de dinheiro para ver sua amada:

Pintou um bode

Vou sair no pinote

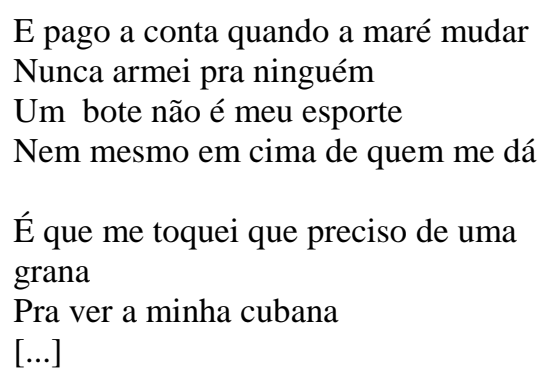

A sua amada, de acordo com a letra, parece possuir condições financeiras melhores, pois "[...] fez lipoaspiração / Ela me avisou que vai mudar seu guarda-roupa / Para desfilar no próximo verão".

Em um momento da letra, o eu lírico denomina a "cubana" como "louca", mas isso não impede de amá-la: "Diz que vai virar um avião / Finjo acreditar pra não haver um bate-boca / É louca mas mora no meu coração".

O tratamento amoroso aqui é diverso do que ocorre na letra do samba "Retiro", no qual há uma imagem bastante idealizada da figura amada, tornanda-a instrumento de dissolução das angústias do eu lírico. Em "Pintou um bode", Paulinho recorre ao humor e à figura tradicional do malandro, tema frequente no início do samba, nas décadas de [19]20 e 30, conforme observa Luciano Cavalcanti:

A malandragem carregaria consigo a ideologia da negação da moral do trabalho e da conduta exemplar, seguido da valorização do prazer, da dança, do sexo e da bebida..." (CAVALCANTI, 2011, p. 6).

Para Carlos Sandroni, o malandro se define

[...] por sua relação esquiva com o mundo do trabalho: trabalha o mínimo possível, vive do jogo, das mulheres que o sustentam e dos golpes que aplica nos otários, sua contrapartida bem comportada. (SANDRONI, 2012, p. 158).

A figura do malandro, apesar de não ser tão frequente no samba de Paulinho da Viola, 
aparece em sambas como "Perdoa", de Memórias cantando, de 1976, e “Que trabalho é esse?”, do álbum A toda hora rola uma estória, de 1982. Em "Perdoa", o tom adotado pelo eu lírico é bem humorado e crítico em relação à situação financeira, dialogando com o já citado "Pode guardar as panelas":

\author{
Meu bem, perdoa \\ Perdoa meu coração pecador \\ Você sabe que jamais eu viverei \\ Sem o seu amor \\ Ando comprando fiado \\ Porque o dinheiro não dá \\ Imagine se eu fosse casado \\ Com mais de seis filhos para sustentar \\ [...]
}

No caso do samba “Que trabalho é esse?”, ainda que possamos associar o eu lírico à figura do malandro, o que se destaca é o senso crítico da personagem em relação à exploração trabalhista tópica bastante frequente na história do samba, revelando "que o trabalho não é visto como expressão de dignidade - como se afirma no senso comum -, mas justamente como sinônimo de exploração e humilhação diárias, de uma violência que marca o corpo e o sujeito, observa Cilene Pereira (2018, p. 97).

Que trabalho é esse

Que mandaram me chamar

Se for pra carregar pedra

Não adianta, eu não vou lá

Quando chego no trabalho

O patrão vem com aquela história

Que o serviço não está redendo

Eu peço minhas contas e vou-ḿembora

Quando falo no aumento

Ele sempre diz que não é a hora

Veja só meu companheiro

A vida de um trabalhador

Trabalhar por tão pouco dinheiro

Não é mole, não senhor

Pra viver dessa maneira

Eu prefiro ficar como estou

[...]
Nas canções de Paulinho da Viola, o amor pode ser visto de formas distintas, ele pode sugerir sua realização, como vimos nas duas canções comentadas, ou fracassar antes de acabar, dando vazão ao próprio samba, vemos na letra de "Pressetimento", do álbum Paulinho da Viola, de 1971:

\author{
Nosso amor não dura nada \\ Mas há de dar um poema \\ Que transformei num samba \\ Quando a gente se deixar \\ Quando a gente se deixar \\ Nosso amor foi condenado \\ A breve amor nada mais \\ Eu tive um pressentimento \\ No nosso último beijo \\ Por isso faço um poema \\ Antes dele se acabar \\ E ponho uma melodia \\ Transformo em um samba vulgar \\ Minha dor e meu lamento \\ Papel que solto no ar \\ $\mathrm{Ai}$ amor que sofrimento \\ Ver meu sonho se acabar
}

Em "Pressentimento", como vemos, o amor não chega a findar, mas dotado de toda uma memória amorosa do fracassso, o eu lírico pressente a brevidade do sentimento, transformando-o (antes que acabe) em canção. Assim, o amor se não dura, perdura, ao menos, em formato de samba, de canção popular.

\section{REFERÊNCIAS}

AZEVEDO, Ricardo. O abençoado e o danado do samba. Disponível em

http://www.ricardoazevedo.com.br/wp/wp-

content/uploads/Abencoado-e-danado-

dosamba1.pdf. Acesso em 10 de jan. 2017.

CAVALCANTI, Luciano Marcos Dias. Música popular e poesia no Brasil: um breve percurso histórico. Revista Darandina. v. 4, n. 1, 2011. Disponível em: http://www.ufjf.br/darandina/files/2011/06/M\%C3 $\%$ BAsica-popular-e-poesia-no-Brasil-um-brevepercurso-hist\%C3\%B3rico.pdf. Acesso em 19 de out. 2018. 
MATOS, Claudia Neiva de. Acertei no milhar: samba e malandragem no tempo de Getúlio. Rio de Janeiro: Paz e Terra, 1982.

MÁXIMO, João. Paulinho da Viola - Perfis do Rio. Rio de Janeiro: Relume Dumará, 2002.

PAULINHO DA VIOLA (Site Oficial).

Disponível em:

http://www.paulinhodaviola.com.br/portugues/.

Acesso em 10 de mar. 2018

PEREIRA, Cilene Margarete. "A dor da gente não sai no jornal: poesia, canção e política. In:

Recorte, Três Corações, v. 13, n. ${ }^{\circ}$ 1, 2016, p. 1-14. Disponível em:

http://periodicos.unincor.br/index.php/recorte/arti cle/view/2785/pdf_84. Acesso em out. de 2018.

PEREIRA, Cilene Margarete. A voz (e a vez) do samba. Revsita Uniabeu, Rio de Janeiro, v. 11, n. ${ }^{\circ}$ 29, 2018, p. 97-112. Disponível em:

http://revista.uniabeu.edu.br/index.php/RU/article/ view/3120/pdf. Acesso em 20 de dez. 2018.

PEREIRA Jr., Luiz Costa. O mar que me navega: sintonias filosófias em Paulinho da Viola. São Paulo: USP, 2011. Dispnível em:

http://www.teses.usp.br/teses/disponiveis/48/4813 4/tde-21072011-131554/pt-br.php. Acesso em 15 de set. 2018.
SANDRONI. Feitiço decente: transformações do samba no Rio de Janeiro (1917-1933). 2. ed. Rio de Janeiro: Zahar, 2012.

SODRÉ, Muniz. Samba, o dono do corpo. $2^{\mathrm{a}}$ Ed. Rio de Janeiro: Mauad, 1998.

ROMANELLI, Francisco. Paulinho da Viola: a filosofia do navegante. Samba de roda, samba da vida: filosofia de botequim em Noel, Paulinho e Chico. Três Corações (Dissertação de Mestrado em Letras/UNINCOR). Disponível em: http://www.unincor.br/images/arquivos_mestrado/ dissertacoes/francisco_antonio_romanelli.pdf. Acesso em 01 de out. 2018.

\section{Sthanley Ogino Zaqueu}

Graduando em Psicologia.

\section{Cilene Margarete Pereira}

Doutora em Teoria e História Literária (UNICAMP); Docente dos Programas de Mestrado em Letras e Profissional em Gestão, Planejamento e Ensino e do Curso de Graduação em Letras (UNINCOR); Editora da Revista Recorte. 